\title{
On Development and Application Prospect of Mobile E-commerce
}

\author{
Huili Wang \\ Wuchang University of Technology, Wuhan Hubei, 430223, China
}

Keywords: Mobile e-commerce, Development, Application prospect.

\begin{abstract}
In the development of wireless mobile technology, the mobile e-commerce begins to get favour from people, which better broadens the running space of our e-commerce industry, allowing for a wider range of e-commerce. Combination of mobile e-commerce and enterprise e-commerce platforms, and connection with computer terminals, smart phones and other related mobile devices, allow fast completion of business transactions. This paper, based on an overview of mobile e-commerce, discusses the main contents of mobile e-commerce, analyzes the current development of mobile e-commerce, and proposes future application prospect of mobile commerce.
\end{abstract}

\section{Introduction}

The rapid development of mobile e-commerce in China is the result of development of the mobile communication and network, and it has an extremely broad market prospect, and gets a great development after generation of the mobile Internet. It services are constantly upgrading, for example, mobile music, mobile QQ, micro-chart, micro-blogging have become mobile network contents very beloved by modern people, which also lays a good foundation for new development of mobile e-commerce. Compared with the real purchasing, after the use of mobile e-commerce means for shopping, customers are often more dependent on online shopping. The reason is that mobile e-commerce is convenient and flexible, adapting to the fast-paced and high-efficiency living conditions of modern people.

\section{Brief introduction of mobile e-commerce}

As a new business transaction way, mobile e-commerce is not restricted by time and space. As long as use the mobile terminal, which are the handheld mobile terminal, we can implement various business transactions under the wireless communication conditions. Mobile e-commerce carriers include mobile phones and computers, which can carry out various e-commerce activities between person to person as long as access to wireless Internet. This type of business will not be limited by time and space, and people can use mobile devices for online shopping, which also provides a new form of commodity trading for traders. And compared with past traditional e-commerce, mobile e-commerce is extremely easy to use. No matter where users are, they can simply get the internet for leisurely shopping. Meanwhile, the use of mobile e-commerce is very flexible. Whether in the tourism process, or in the course of the party, as long as there is a moment, people and use without the need to stay in front of the desktop computer. Of course, mobile e-commerce also has strong personalized characteristics. Users' shopping behaviors are completely private, able to set up on their own.

\section{Main content of mobile e-commerce}

Mobile e-commerce can be said to be the perfect combination of network technology and modern mobile communication technology. In a long period of development process, types of service are becoming increasingly diversified. Currently, the main services of mobile e-commerce are as follows. 
First, mobile e-commerce transactions. Because the mobile e-commerce has the salient feature of immediacy, it is very popular in the stock trading process. Mobile carriers can allow users to access relevant information anytime and anywhere, but also conduct online management on stock trading after order confirmation. Second, mobile e-ticketing services. Users can use the mobile network technology to book train tickets, air tickets and visit tickets and other services. Of course, now the mobile e-commerce business scope is still continuing to be expanded. The business transaction way provides customers with a great convenience. For example, when a certain flight is suddenly canceled, or some commodities suddenly begin to engage in promotional offers, the mobile e-commerce is able to provide information to consumers as soon as possible. In addition, when users use mobile e-commerce to purchase goods, they are able to view information on similar products, read comments, and browse related news, thereby facilitating users for comprehensive assessment and choosing want they are most satisfied with. Third, mobile e-banking business. Mobile e-commerce can provide a great convenience for users' personal financial management, and can use the network bank for improvement and perfection, to facilitate the majority of users to quickly query and check their accounts, and quickly complete transfers and payments and other steps, and receive the payment notice. Fourth, mobile e-commerce entertainment services. This form of e-commerce can not only facilitate consumers for shopping, but also provide appropriate entertainment services. For example, consumers can use the internet and mobile devices to listen to wonderful music. At the same time, they can also download or order certain songs, of course, and co-play online games with friends, to enrich their lives. Fifth, mobile e-health services. Consumers can completely use network technology to obtain important medical information in a timely manner. Today, the mobile e-commerce is widely used in the medical industry. Once the patient is in a state of crisis, the ambulance can be used as a temporary treatment site, and the wireless network technology is used to achieve exchange of information between the patient's family and medical institutions, so as to save more valuable time for the patient, allowing doctors and patients benefit from it.

\section{Development status of mobile e-commerce}

First, the size of users is rapidly expanding, thus contributing to the expanding market size. Mobile technology mainly refers to the data transmission and resource sharing implemented by laptops and mobile phones and other mobile devices under the wireless network conditions. Its role is to provide useful and accurate information to all customers at all times and in all locations. Based on a survey of China Internet Network Information Center, Internet devices of China's Internet users gradually are concentrated towards mobile phones. By the end of 2015, the number of China's mobile Internet users reached 620 million, increased by $4.3 \%$ compared with the previous year. Especially great popularity of high-performance intelligent mobile terminals and wireless networks promotes the realization of large-scale development of mobile e-commerce. Today, China's mobile Internet is entering into a new era of mobile e-commerce. As of January 2016, the number of China's domestic mobile e-commerce users reached 412 million, increased by more than 25\%compared with the previous year. Seen from Taobao's sales data, at least $60 \%$ of transactions come from the wireless terminals. Traditional e-provider mode in the PC era has very quick realized transfer and the new mobile e-provider era has officially arrived. Second, the rapid development of technology promotes the great development of mobile e-provider industry. Technological advances promotes the healthy development of mobile e-provider business, and the development of mobile e-commerce proposes higher requirements on technology, in particular two-dimensional code technology and image recognition technology well shorten the distance between users and providers, more widely used in social contact and payments and so on. Convenient and secure payment means is one very important aspect in developing mobile e-providers. Today, a lot of social software has the function of payment and transfer and other various functions, allowing users not rely on traditional financial institutions to pay. Good technology can help continuously improve users' experience and analyze customers' behaviors, but also enhance their trust and loyalty degree, which of course is a great driving force to promote the development of mobile e-providers. Third, users' needs are more personalized and 
diversified. As the network technology is changing, under the mobile Internet-based environment, users' demands are real-time, fractional, personalized and diversified. They are no longer just the passive recipient of all kinds of information, but have become the selector and creator. With the continued development of mobile Internet technology, there have been more and more enterprises to join the tide of mobile e-commerce. Under such circumstances, how to better grasp the psychology of consumers, provide them with what they may be interested in, and enhance their loyalty, should be the focus mobile e-commerce businesses need to analyze in future, directly related to its future development.

\section{Application prospect of mobile e-commerce}

\section{Transition from entities to business}

Judging from the development prospect of China's mobile e-providers, transformation from entities to business is one of the very important trends, but also the continuous expansion of business model in the future. Based on the current market-oriented economic development of our country, all kinds of industries are now gradually entering the new age of information and network. In addition to that e-commerce can provide extremely broad base conditions, therefore, the transformation speed and pace toward e-commerce are promoted in all kinds of industries. Under China's current market conditions, there has been a lot of new e-provider development platforms fully developed. For example, when using Taobao, Jingdong, Ali and other large online malls for shopping, these users can shop fast, thus promoting the continuous development of mobile e-commerce. Moreover, some small platforms and applications are also developing at a rapid speed, and constantly promote the upgrading of e-provider platform based on their own improvement. For the development of mobile e-provider market, young people are very strong main reserve consumption force. Use of mobile e-commerce by users, can maintain a prominent role of mobile e-provider market stable operation.

\section{Achieving expansion of market size}

Due to continuous changes of our economy and society, mobile e-provider market share will inevitably get bigger and bigger. For the current market situation, the mobile e-provider has covered a lot of businesses, including household and industrial products, to a large extent, contributing to the smooth functioning of the mobile e-providers. Industries in some places have even created specialized mobile e-provider trading platforms, thus honestly bringing e-commerce into entities. For example, one certain trading mall builds the specialized e-provider platform especially for footwear sales. Footwear manufacturers directly ship products sellers' shops and sellers subsequently use the mobile network platform to promote sales, then to complete transactions, and finally use the express to deliver products to consumers. This saves a lot of intermediate links during sales, thereby greatly reducing the cost of goods, and also provides high-quality products for the majority of consumers, therefore, it will favoured by people. In the future development process of mobile e-provider, mobile e-provider market will become increasingly large, so as to promote new development of China's mobile e-providers.

\section{Unification of convenience and security}

For the majority of mobile e-providers, the convenience is the greatest strength. In the future development process, mobile e-commerce will continue to adhere to the concept, so as to bring consumers more convenient service. Although our current mobile e-providers have showed very strong convenience in the shopping, users can directly use mobile e-commerce platform to complete the payment work, but in the logistics and transport process, there are some issues yet to be resolved. All products sometimes will take a very long time to be able to truly be delivered to users, not showing convenience of e-providers. Therefore, in terms of improving the convenience of mobile e-commerce platform, a large number of issues still need to be solved. Meanwhile, the security issue of mobile e-providers has always been the topic that each consumer are highly concerned about, in 
particular, to pay more attention to the user's own information as well as security and confidentiality of payments. For consumer groups, it can create a more robust information protection mechanism, to strengthen the effective protection of consumers' personal information through a plurality of different links. For payment security, they should be more fully aware of the danger of leaks and in advance as possible strengthen security measures, perfect the reasonable financial protection system and effectively protect the legitimate rights and interests of consumers.

\section{Promoting cooperation and diversification}

For mobile e-commerce, cooperation and diversification development has become one of very important trends, bound to become the mainstay of the socialist market economy with Chinese characteristics. Cooperation development often refers to cooperation between enterprises in various fields to create a more perfect mobile e-provider development system. For example, some large businesses will cooperate with each other to create their own unique logistics enterprises, and implement the militarization management to ensure that e-commerce enterprise employees can preserve the confidentiality of users' information. At the same time, they can also create specialized service carriers. In some major cities, build a solid platform for e-commerce services, and after consumers complete payments, based on the location of the consumer implement goods distribution work, so that users will not wait too long, as a result, to reflect the convenience mobile e-providers. Of course, based on promoting cooperation development of mobile providers, accelerate the pace of their diversification, with a focus on business diversification. For example, all brands of shoes production enterprises can strengthen cooperation, and introduce more diversified new products, thus providing more convenient new shopping options for users.

\section{Conclusion}

Overall, mobile e-commerce has good prospect for development. The rapid development of mobile e-commerce is not only the rare opportunity for development, but also a very big challenge for operators. Currently mobile devices have been very popular, which is a good driving force for the development of this business, and this business development model, to a very large extent, changes consumption concepts of modern people. In the future mobile e-commerce development process, this model will continue to change people's lives, and provide greater convenience.

\section{References}

[1] Gong Xiufang. Analysis on Situation and Development Prospect of Mobile E-commerce, E-Commerce, 2013 (11).

[2] Zhang Lijuan. Discussion on Mobile E-commerce Development Trend, Modern Economic Information, 2014 (5).

[3] Zhao Lei, Tang Wei. Business on Fingertips - Analysis on Mobile E-commerce Development Trend, Chinese E-commerce, 2014 (2).

[4] Qie Jun, Li Yanxin. On Development Trend of Mobile E-commerce, Industry and Science \& Technology Forum, 2014 (24).

[5] Gu Chunjie. Study on Mobile E-commerce Development Trend, Chinese Commerce, 2015 (3).

[6] Jiang Haiyang, Ceng Jianqiu. LBS-based Mobile E-commerce Marketing Model and Trend, Journal of Beijing University of Posts and Telecommunications (Social Science Edition), 2015 (2). 